\title{
THE INVESTIGATION OF THE CAVITATION PHENOMENON IN THE LAVAL NOZZLE WITH FULL AND PARTIAL SURFACE WETTING
}

\author{
JABLONSKÁ Jana1, KOZUBKOVÁ Milada1, ZAVADILOVÁ Barbora², \\ ZAVADIL Lukáš ${ }^{3}$, FIALOVÁ Simona ${ }^{4}$ \\ ${ }^{1}$ VŠB-Technical University of Ostrava, Faculty of Mechanical Engineering, Department of Hydromechanics and \\ Hydraulic Equipment, 17. listopadu 15, 70833 Ostrava - Poruba, Czech Republic, \\ email: jana.jablonska@vsb.cz, milada.kozubkova@vsb.cz \\ ${ }^{2}$ SIGMA GROUP a.s., Jana Sigmunda 313, 78349 Lutin, Czech Republic \\ ${ }^{3}$ CENTRUM HYDRAULICKÉHO VÝZKUMU spol. s r.o., Jana Sigmunda 313, 78349 Lutín, Czech Republic \\ ${ }^{4}$ VUT-Brno University of Technology, Faculty of Mechanical Engineering, Victor Kaplan Department of Fluids \\ Engineering, Technická 2896/2, Brno, Czech Republic
}

\begin{abstract}
The article deals with the cavitation phenomenon affected by full and partial wetting of the wall. For the numerical computation of flow in the Laval nozzle the Schnerr-Sauer cavitation model was tested and was used for cavitation research of flow within the nozzle considering partial surface wetting. The coefficient of wetting for various materials was determined using experimental, theoretical and numerical methods of fluid flow due to partial surface wetting.
\end{abstract}

KEYWORDS: partial wetting, measurement, cavitation, CFD, Ansys Fluent, Laval nozzle,

\section{Introduction}

Wettability (hydrophilicity) is the ability of liquid to wet a substance to form a continuous fluid layer on the surface. Generally the surfaces are considered as wettable ("no slip" condition), when the relative velocity of the fluid is zero. The velocity profile and pressure drop at the fluid flow through a pipeline can be influenced by physical properties of the liquid or the pipe coating.

Conversely partial wetting (not wetting to the limiting case) is a property in which the liquid poorly wets the surface of the second phase. The level of liquid wetting depends on the level of the surface tension reduction. Large surface tension impedes the wetting process. The relative velocity of the flowing liquid at the wall is not zero.

To create a new surface, it is necessary to spend a certain amount of work - surface energy. Thus the greater the surface energy of the solid material, the more the material becomes hydrophilic (solid surfaces wetted by water). Conversely, hydrophobic (poorly wetted surfaces with water), i.e. not wettable or partially wettable materials represent materials with low surface energy. Suitable surface treatment of hydraulic elements prevents the occurrence of cavitation. Cavitation during the liquid flow is a current issue in the context of increasing the operating parameters of hydraulic systems. Cavitation in hydraulic elements is undesirable since it causes deterioration of the surface material in hydraulic elements and is accompanied by noise and vibration. [1], [2], [3] 
The article deals with the cavitation phenomenon and the affect of full and partial wetting of the walls using experimental and mathematical methods followed by their evaluation.

\section{Theory of partial wettability and cavitation}

\subsection{Partial Surface Wetting and determination of adhesive coefficient}

Fluid flow is given by two of the following equations, which express the basic physical laws [4], [18]. The continuity equation expresses the law of mass conservation and the Navier-Stokes equations express the law of momentum conservation. Their solution is supplemented with boundary and initial conditions.

In references [10], [16] special boundary conditions were defined, e.i. boundary condition for a generally curved surface in contact with a liquid (1) assuming that: If the liquid is slipping on the surface by velocity $\vec{c}$, the adhesive shear stress vector $\vec{\sigma}$ lays in a plane defined by an outer normal vector $\vec{n}$ to the surface, velocity vector $\vec{c}$ [10] and wall shear stress vector $\vec{\sigma}_{\mathrm{A}}$ (see Fig. 1.):

$$
\vec{\sigma}_{\mathrm{A}}=(\vec{\sigma} \times \vec{n}) \times \vec{n}=-k \vec{c}
$$

where $\mathrm{k}$ is the adhesive coefficient $\left[\mathrm{Pa} \cdot \mathrm{s} \cdot \mathrm{m}^{-1}\right]$. On the basis of this conception, it is possible to assume that the vector of shear stress on a partially wettable surface is proportional to the liquid velocity.

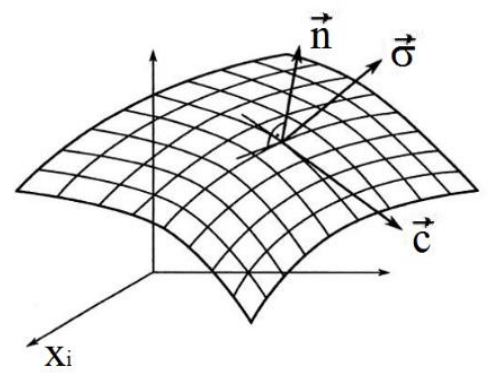

Fig. 1 Shear stress on a general curved surface [10]

According to [17], a mathematical model of the adhesive force is derived based on the droplet motion on an inclined plane.
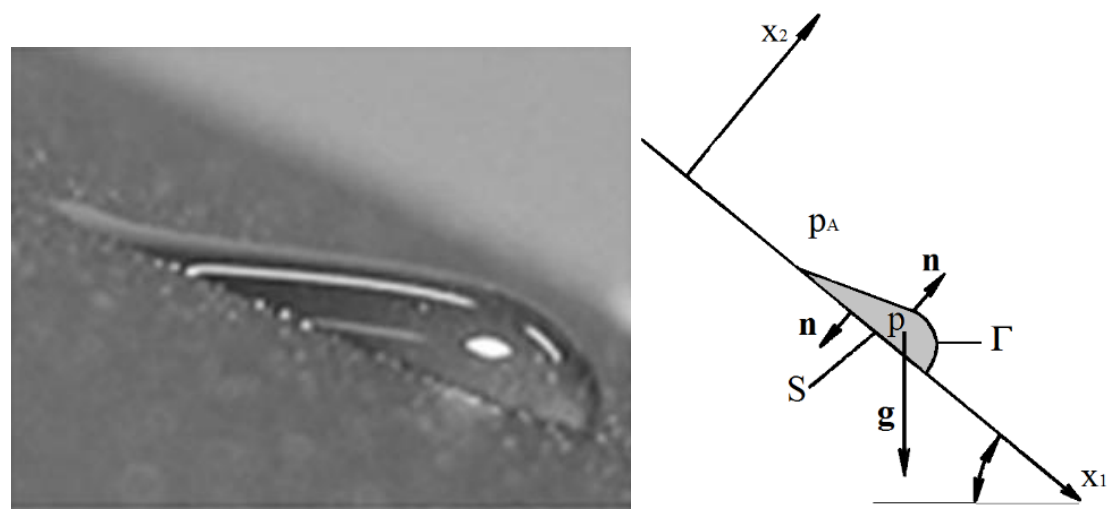

Fig. 2 Droplet motion on an inclined plane

Fig. 2 shows the droplet motion along an inclined plane, where the translational motion of the droplet along axis $x_{1}$, with a speed $c_{1}$ at each point of the motion is considered. The equation for the adhesive force is derived from Navier-Stokes equations. The initial conditions are given as follows: 
For $t=0: x_{1}=0$ and $\dot{x}_{1}=c_{1}$

This defines the droplet motion on an inclined plane, where the equation in time $t=0$ is in the form:

$$
\dot{x}_{1}=\left(c_{1}-\frac{f}{S \cdot k}\right) e^{-\frac{S \cdot k}{m} t}+\frac{f}{S \cdot k}
$$

The assumption of $k \neq f\left(c_{1}\right)$ prevents the calculation of the adhesive coefficient $\mathrm{k}$ from the measured values, that are known from the measurement on the ultra-hydrophobic materials [16]. The adhesive coefficient $\mathrm{k}$ was detected numerically from an exponential function of measured velocities that correspond with equation (2). The form of the solved equation is:

$$
y=A \cdot e^{B t}+C
$$

The unknown coefficients $A, B$ and $C$ from the equation (2) are determined by the method of least squares that enables the calculation of the unknowns: $k, c_{1}, f$.

\subsection{Mathematical model of cavitation}

Multiphase model for modelling cavitation with individually modelled phases of water and vapor must be used. There exist several cavitation models which differ in their approach to the solution of cavitation and in input parameters. All the cavitation models are based on the linearized Rayleigh-Plesset equation (4) [2], [5], [19], [20]:

$$
\frac{p_{B}(t)-p_{\infty}(t)}{\rho_{l}}=R \frac{d^{2} R}{d t^{2}}+\frac{3}{2}\left(\frac{d R}{d t}\right)^{2}+\frac{4 v_{L}}{R} \frac{d R}{d t}+\frac{2 S}{\rho_{L} R}
$$

where $p_{B}(t)$ is the pressure in the bubble, $p_{\infty}(t)$ is the pressure around the bubble, $\rho_{L}$ is the density of the liquid, $v_{L}$ is the kinematic viscosity of the liquid, $R$ is the radius of the bubble, $S$ is the bubble surface.

For numerical modelling ANSYS Fluent software was used. Cavitation models available in this software are the Singhal, Schnerr-Sauer and Zwart-Gerber-Belamri models. The models Schnerr-Sauer and Zwart-Gerber-Belamri are more stable and have faster convergence of the solution. Therefore, the user's manual of the ANSYS Fluent 13.0 software [6], [7] recommends their use. The Schnerr-Sauer, Zwart-Gerber-Belamri and Singhal cavitation models were tested for the problem of cavitation in the Laval nozzle and its results were compared with experiment [8]. The Schnerr-Sauer cavitation model was chosen due to better numerical properties.

This model is compatible with the Eulerian multiphase mixture model. The parameters for setting this model are

- vapour pressure 2368,7 Pa,

- number of bubbles $10^{10}$

The value of the saturated vapour pressure depends on temperature. The pressure of saturated vapour $2368,7 \mathrm{~Pa}$ corresponds to a temperature of $20^{\circ} \mathrm{C}$. [9]

\section{Experimental evaluation of adhesive coefficient and cavitation}

The samples used for the measurement were coated metal sheets (samples designation: TC1191, TC3072 and TC4111). The measured liquid was water at ambient temperature 
$\mathrm{t}=22^{\circ} \mathrm{C}$. [17] A Nikon D300s camera set to capture maximum video resolution of $1280 \mathrm{x}$ 720 pixels was used for recording the droplet motion on an inclined plane. The plate tilting and accurate angle setting of $\alpha$ was performed utilizing a tilt table with electric motor. The measured values have been processed by the use of commercial software Office Excel and the adhesion coefficient, the function $f$ along with the initial speed of the $c_{l}$ was determined using Matlab software. Fig. 3 shows the measuring device and its scheme, the camera was placed on an adjustable tripod.
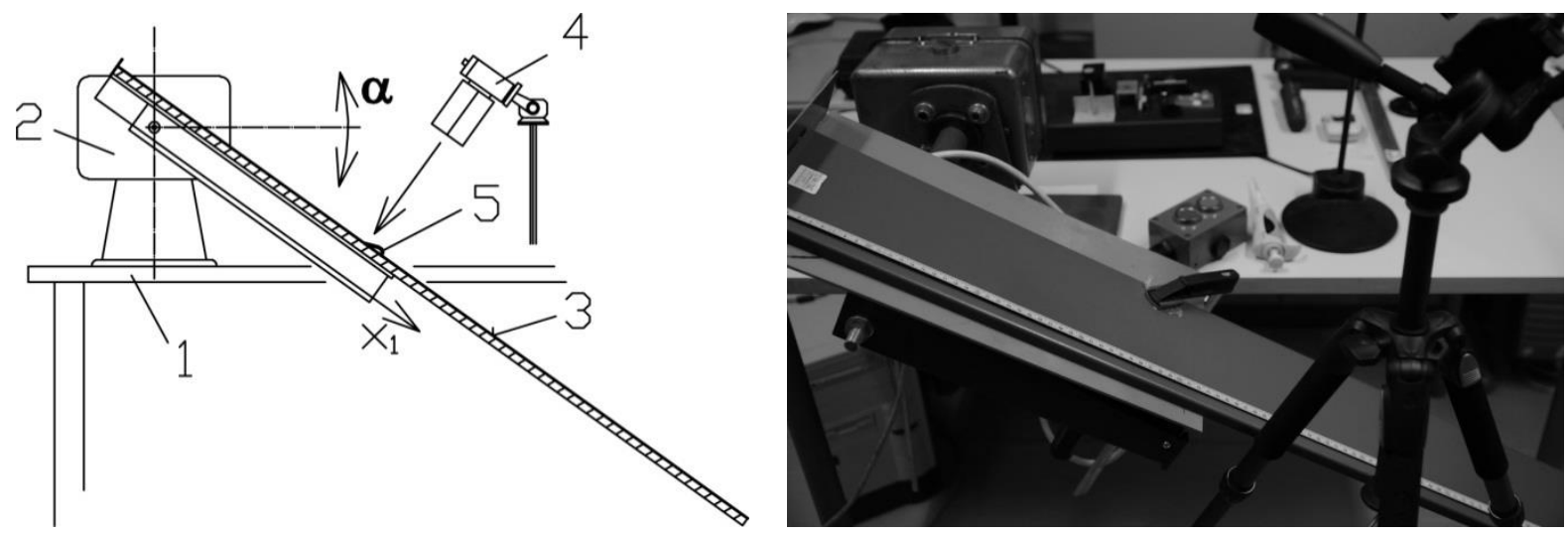

Fig. 3 Scheme of the measuring device: 1 - table, 2 -inclining mechanism with electromotor, 3 - measured material, 4 - camera Nikon D300s, 5 - droplet.

The adhesive coefficient values $k$ for all three measured materials are shown in the following Table 1.

Table 1 . The adhesive coefficient values $k$

\begin{tabular}{|c|c|}
\hline Material & $\mathrm{K}\left[\mathrm{Pa} \cdot \mathrm{s} \cdot \mathrm{m}^{-1}\right]$ \\
\hline TC1191 (black) & 1,6011 \\
\hline TC3072 (metallic) & 1,3368 \\
\hline TC4111 (green) & 1,3264 \\
\hline
\end{tabular}

Generally the hydrophobicity effect can be used in different industrial areas, for example in water aeration or rime elimination. Surface hydrophobicity has a great influence on friction losses in the fluid flow in both pipeline systems and complex shapes of hydraulic elements. Currently, different hydrophobic surfaces using plasma jets have been prepared and new variable plasma technologies are developed.

The physical experiment of cavitation was accomplished in a laboratory at VŠB-TUO to study the development and behavior of cavitation in flowing water within a hydraulic circuit utilizing the Laval nozzle with circular cross section, see Fig. 4. 


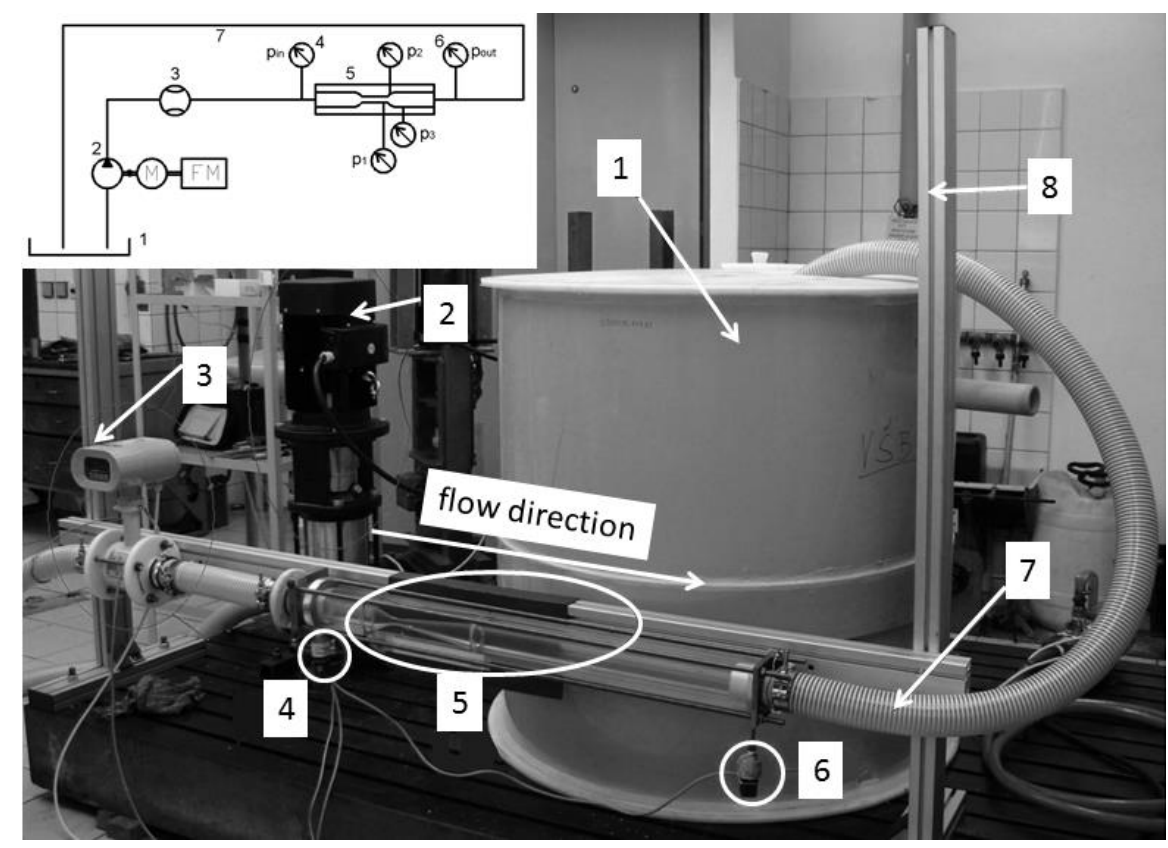

Fig. 4. Hydraulic circuit with Laval nozzle of circular cross section: 1 - polypropylene cylindrical tank, 2 - centrifugal pump of the CR type with a YASKAWA converter, 3 - Flonet induction flowmeter, 4 - pressure sensor at inlet, 5 -Laval nozzle made from transparent material Tecanat and pressure sensors and a Hydac HMG3000 device, 6 - pressure sensor at outlet, 7 - NASSA type pipe

The geometry of the most important central part is described in Fig. 5, where in the narrowing nozzle the cavitation was observed. The narrowest place of the nozzle was selected as the origin of the coordinates system and the $\mathrm{x}$-coordinate value as $0 \mathrm{~m}$.

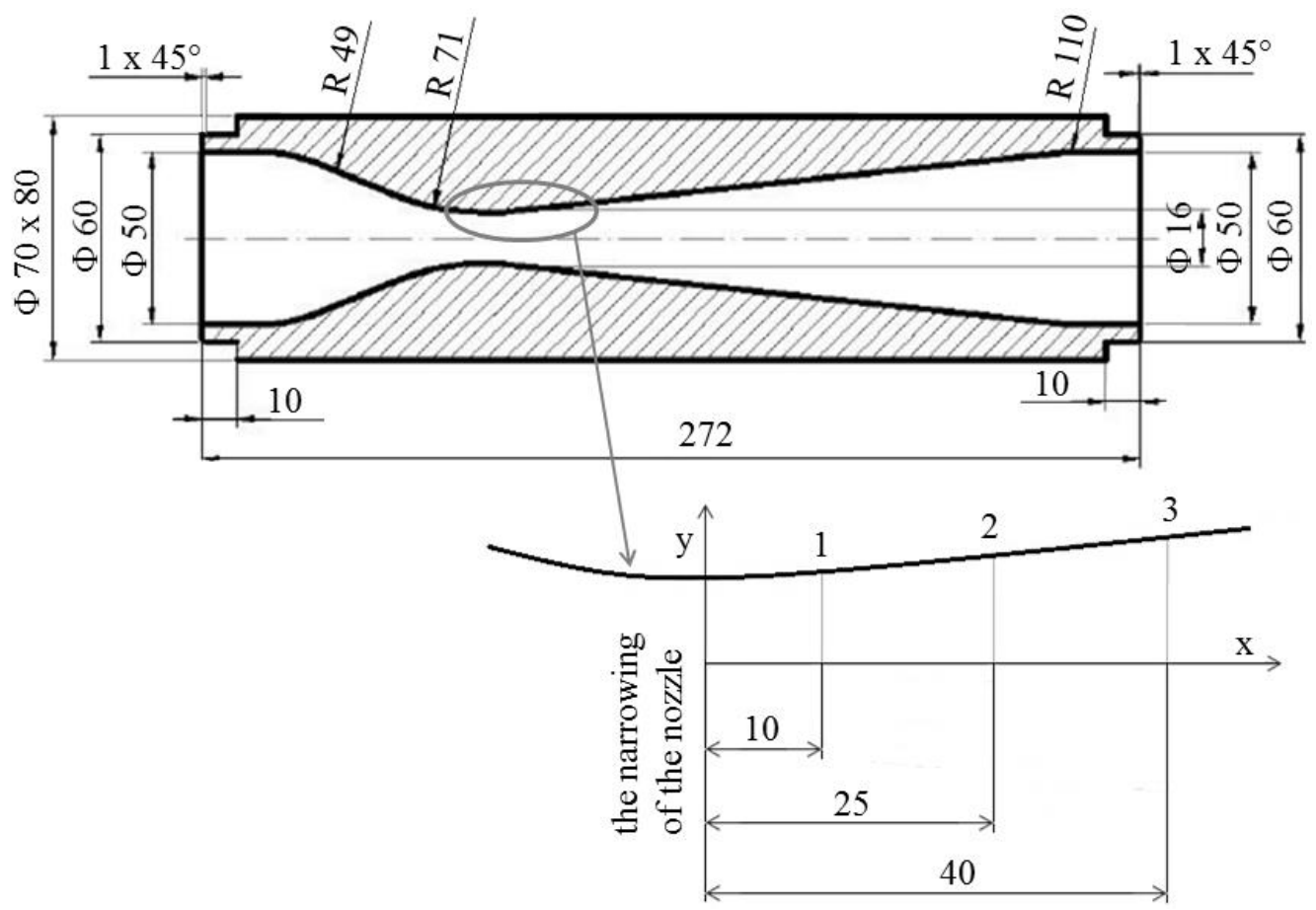

Fig. 5. The geometry of the central part and position of three sampling places behind the narrowing of the Laval nozzle [mm] 
The inlet and outlet static pressure and inlet flow rate were measured. During the experiment a constant water mass flow rate was used $(3 \mathrm{~kg} \cdot \mathrm{s}-1)$. The atmospheric pressure in the laboratory was $97393,68 \mathrm{~Pa}$. The static pressures on the inlet psin and outlet psout were measured by a relative pressure sensor with a range of (-1 to 9) bar and their constant absolut values were $\operatorname{psin}=165052 \mathrm{~Pa}$, psout $=105536 \mathrm{~Pa}$.

In specific sampling places 1,2 and 3 , which means $\mathrm{x} 1=0,01 \mathrm{~m}, \mathrm{x} 2=0,025 \mathrm{~m}$ and $\mathrm{x} 3=0,04 \mathrm{~m}$ behind the narrowing place (see Fig.5) of the nozzle in the cavitation area, the measurement of the static pressure was performed by a relative pressure sensor and a Hydac HMG3000 device. In order to increase the accuracy of the measurements a pressure sensor with a range of ( -1 to 1$)$ bar was used for all sampling points. It was observed that the cavitation area in the divergent part of the nozzle was unstable. Cavitation area during the experiment changed size and shape and it was possible to observe a periodic oscillation of the field. Therefore the measurement was made for three different sampling periods of the measuring device: $0,5 \mathrm{~ms}$ for a recording time of $60 \mathrm{~s}$ and $5 \mathrm{~ms}$ and $10 \mathrm{~ms}$ for a recording time of $120 \mathrm{~s}$. Table 2 presents the time average values of the absolute static pressure at three sampling points.

Table 2. Average values of absolute static pressure at three sampling points $[\mathrm{Pa}]$

\begin{tabular}{|c|c|c|c|c|}
\hline \multirow{2}{*}{$\begin{array}{c}f \\
\mathrm{~ms}\end{array}$} & $t$ & \multicolumn{3}{|c|}{ Sampling point $\mathrm{m}$} \\
\cline { 3 - 5 } & $\mathrm{s}$ & 0,01 & 0,025 & 0,04 \\
\hline 0,5 & 60 & 2587,05 & 11638,61 & 58147,07 \\
\hline 5 & 120 & 3049,81 & 11608,06 & 58230,83 \\
\hline 10 & 120 & 3034,06 & 11654,48 & 58166,60 \\
\hline
\end{tabular}

The cavitation field, its size and shape is presented in Fig. 6. The approximate length of the cavitation area was measured at about $35 \mathrm{~mm}$. It is possible to estimate length only by observing with the eye, but it can be wrongly interpreted at places where vapour and gentle vapour pulls appear.

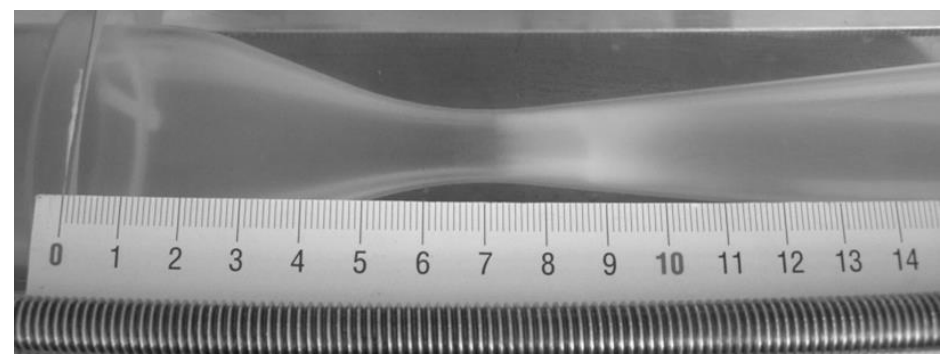

Fig. 6. The cavitation area behind the narrowing of the nozzle

\section{Cavitation Area - the Results of Numerical Computation in Ansys Fluent Software}

The investigation of the flow in the nozzle was conducted by the Schnerr-Sauer cavitation model. 
The flowing medium in the nozzle was a mixture of water and vapour. A diagram of the computational area comes from the geometry of the Laval nozzle used in the physical experiment, see Fig. 7.

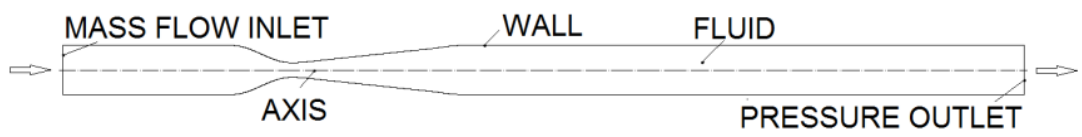

Fig. 7. Boundary conditions of the computational nozzle geometry

Due to the simple nozzle geometry, the problem was modelled as an axi-symmetric transient case and completed within ANSYS Fluent 13.0. The flow in the Laval nozzle can be considered turbulent with a Reynolds number $\mathrm{Re}=75000$, so the two-equation turbulent model $k-\varepsilon$ RNG. „Enhanced Wall Treatment" is defined for modelling of the flow near the wall to include the viscous layer in relation to the gradient of the mesh in the direction of the wall. The case was solved as a two phase viscous Mixture model (water and vapour).

At the entrance into the Laval nozzle the flow rate condition „Mass Flow Inlet“ of water $3 \mathrm{~kg} \cdot \mathrm{s}^{-1}$ was set. The output condition from the nozzle was defined as the pressure condition for the mixture „Pressure Outlet“" with an outlet pressure of $105536 \mathrm{~Pa}$. Other boundaries were defined as a wall „Wall”, see Fig. 7.

The graph in Fig. 8 presents the mean numerical static pressure on the wall of the nozzle and the values of the measured static pressure from the physical experiment at particular sampling points.

We can see that the model describes the static pressure progress differently at the narrowest place of the nozzle, where the value of vapour pressure is $2368,7 \mathrm{~Pa}$ and then increases rapidly. The input pressure is about $162000 \mathrm{~Pa}$ and the output pressure is $105536 \mathrm{~Pa}$.

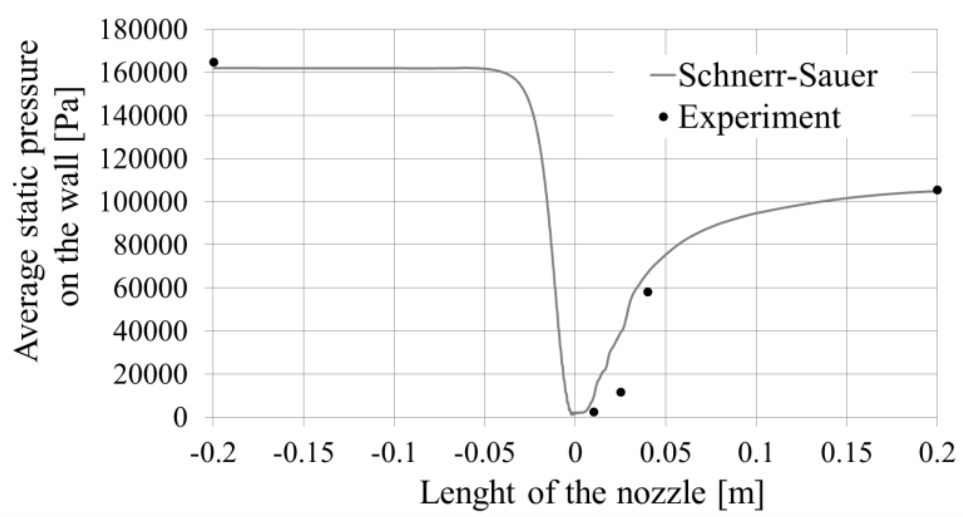

Fig. 8. Mean static pressure on the wall of the nozzle and the values of measured static pressure in all sampling places

As follows from Fig. 8, the values of static pressure from the Schnerr-Sauer cavitation model are similar to the values measured in the physical experiment at all sampling points.

In the contours of velocity (Fig. 9) we can observe that at the input to the narrowest place of the nozzle, the velocity of flowing liquid is highest and decreases lengthwise toward the nozzle. The mean static pressure corresponds to Bernoulli equation; in the narrowest place the pressure is the lowest and with the diffusion of the nozzle it increases. The liquid inversely flows here and begins to swirl, which is characterized by a negative velocity value. 


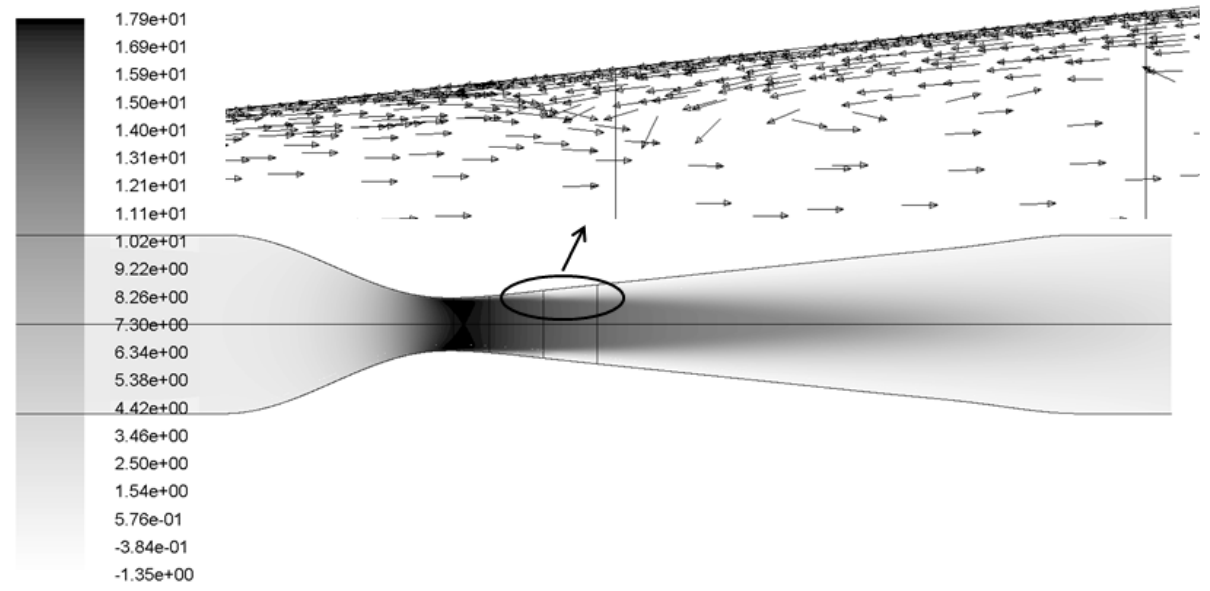

Fig. 9. Contours of the mean axial velocity $\left[\mathrm{m} \cdot \mathrm{s}^{-1}\right]$

In the narrowest place of the nozzle, where the pressure decreases with the vapour pressure value, cavitation is observed. The contours of mean vapour volume fraction and length of the cavitation area can be observed in Fig. 10.
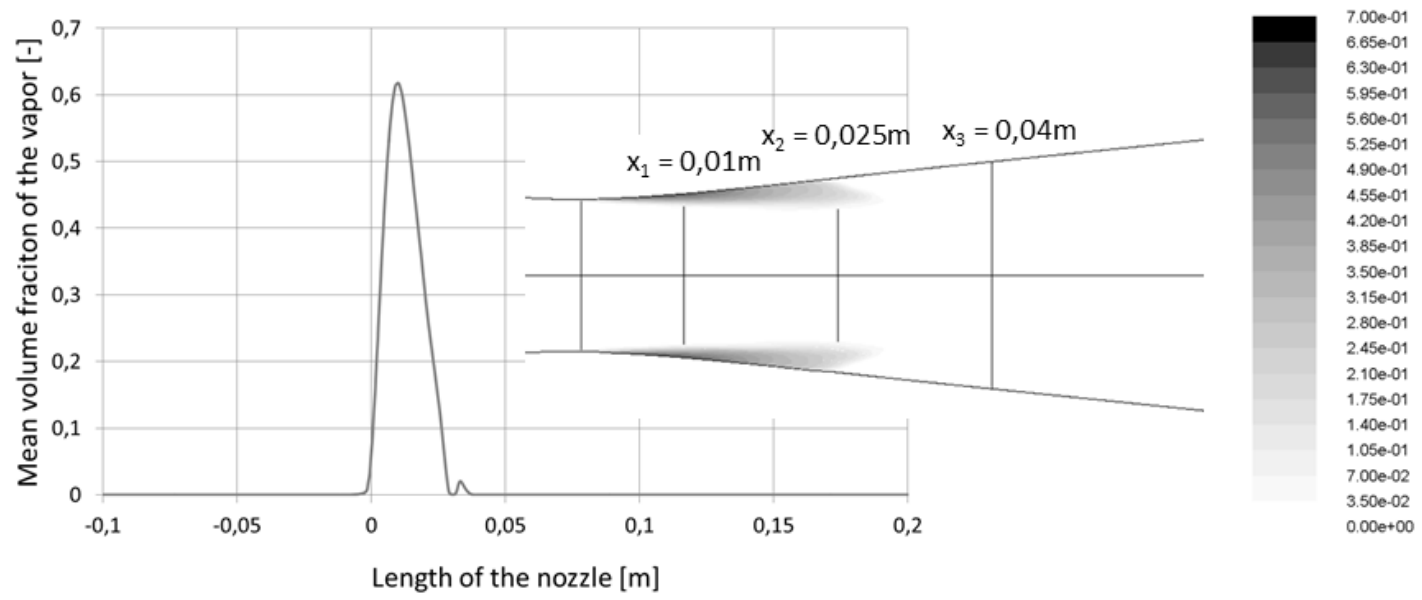

Fig. 10. Mean vapour volume fraction contours and size of the cavitation length

From a comparison of the averaged pressure values and the size of the cavitation field with the experimental results, it follows that the mathematical model of cavitation is convenient.

\section{$5 \quad$ Cavitation Area for Partial Surface Wetting}

The same cavitation model was used for water flow with cavitation in the Laval nozzle with partial surface wetting. The boundary condition of partial wetting was defined by a user defined function UDF (see equation (1)) with predefined adhesive coefficient $k$. It is evident that for a less adhesive coefficient the surface is less wettable and the liquid slips over it.

The influence of partial surface wetting on laminar liquid flow in the tube with a circular cross section was investigated; see Literature [11], [12], [13], [14], [15]. The numerical results were compared with theory and it was confirmed that a laminar velocity profile has an exactly given parabolic shape. The shape of the turbulent velocity profile in the nozzle can't be determined, so we must give up these assumptions. The velocity on the wall must be in the following interval of values: from zero value (no slip condition) to the mean value of the flow velocity which corresponds to a zero value of wall shear stress. For this area the inlet and outlet boundary conditions were the same as in previous research. 
The pressure drop and length of cavitation area was changed with respect to various adhesive coefficients. By decreasing the value of the adhesive coefficient $\mathrm{k}$, the value of the pressure drop and the length of the cavitation area decrease as well, see Fig. 11, 12, 13.

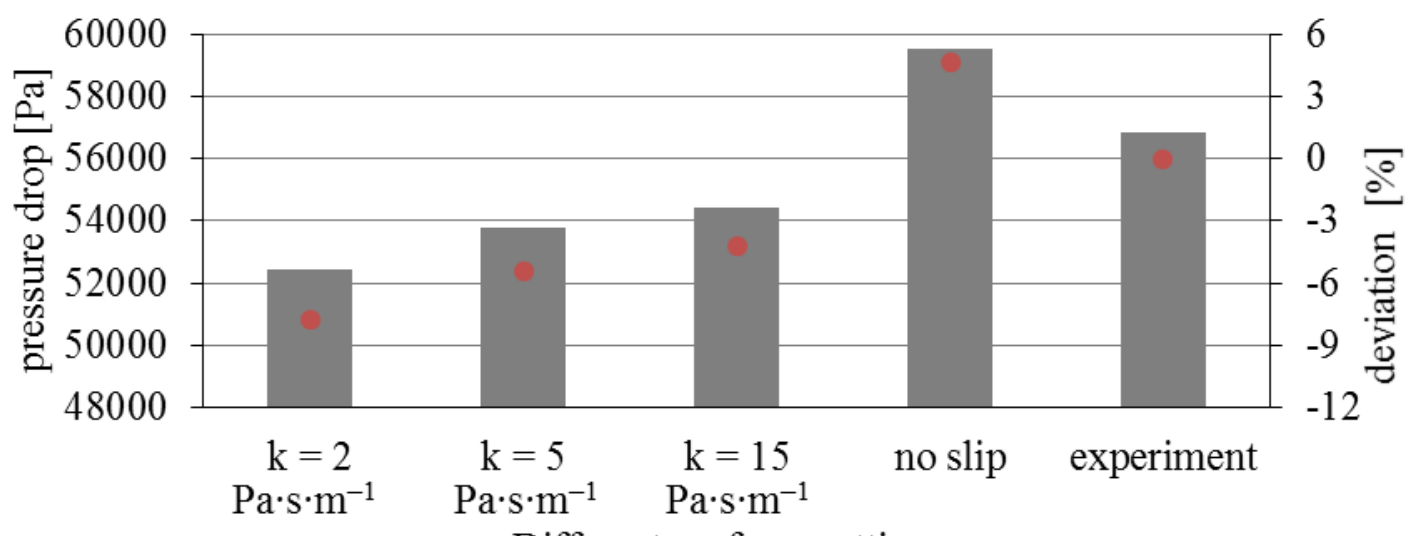

Different surface wetting

Fig. 11. Pressure drop and deviation in the nozzle for different wettable surfaces [Pa]

In Fig. 12 the cavitation area observable by eye is long for the boundary between dark and bright colours of columns in the graph. Observing the bright colour of the columns, there is an area of so-called "pulls of vapour" which has a minimal value of volume fraction of the vapour. The vapour volume is not much more in partial wetting than that by full wetting. It is only spread to the length by the flow of the liquid, and after that the length of the cavitation area increases.

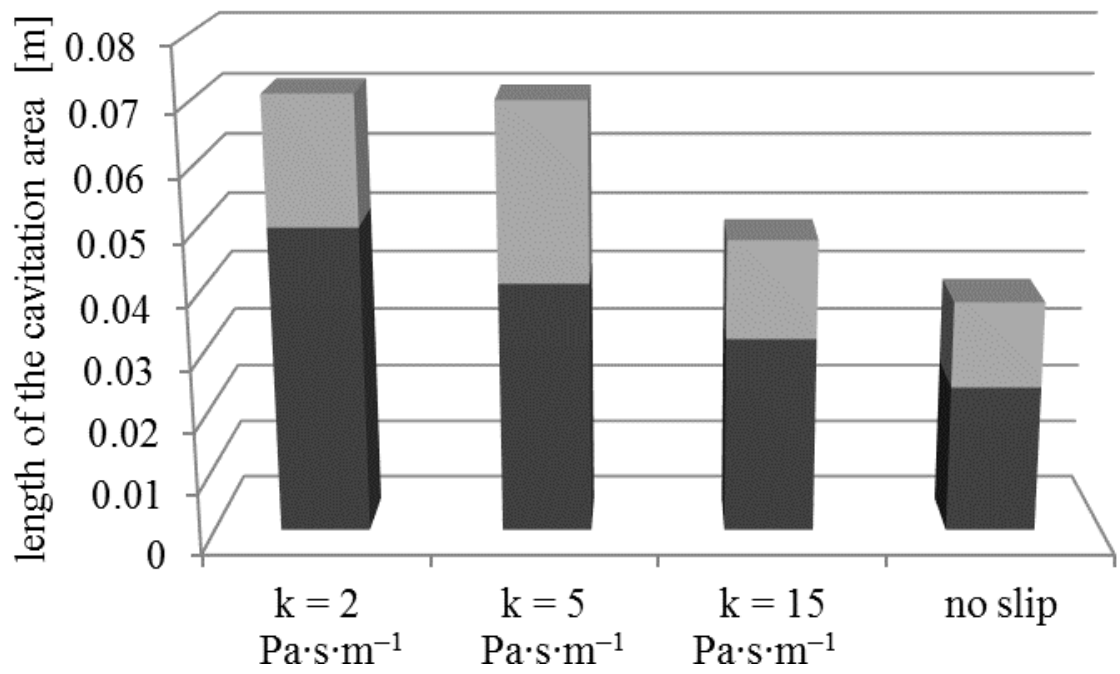

Fig. 12. Cavitation length for different wettable surfaces 


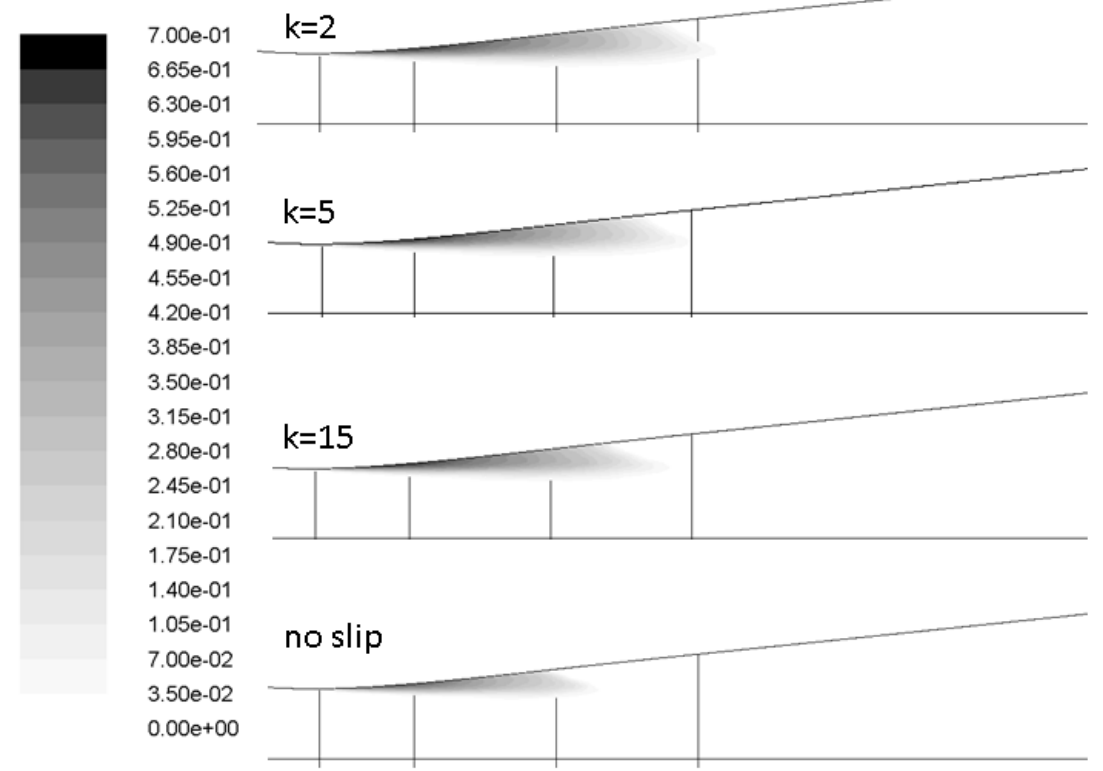

Fig. 13. Cavitation area for different wettable walls of the nozzle - a partially wettable wall with $\mathrm{k}=2,5$, and $15 \mathrm{~Pa} \cdot \mathrm{s} \cdot \mathrm{m}^{-1}$, a fully wettable wall with „no slip“ condition

In the narrowest place of the nozzle the values of the mean axial velocity near the wall in the cavitation region are showed in the graph in Fig. 14. With decreasing value of adhesive coefficient $k$ the velocity of the liquid increases. This corresponds with the partially surface wetting theory. It is apparent that the negative velocity in the narrowest place of the nozzle is caused by secondary vortices.

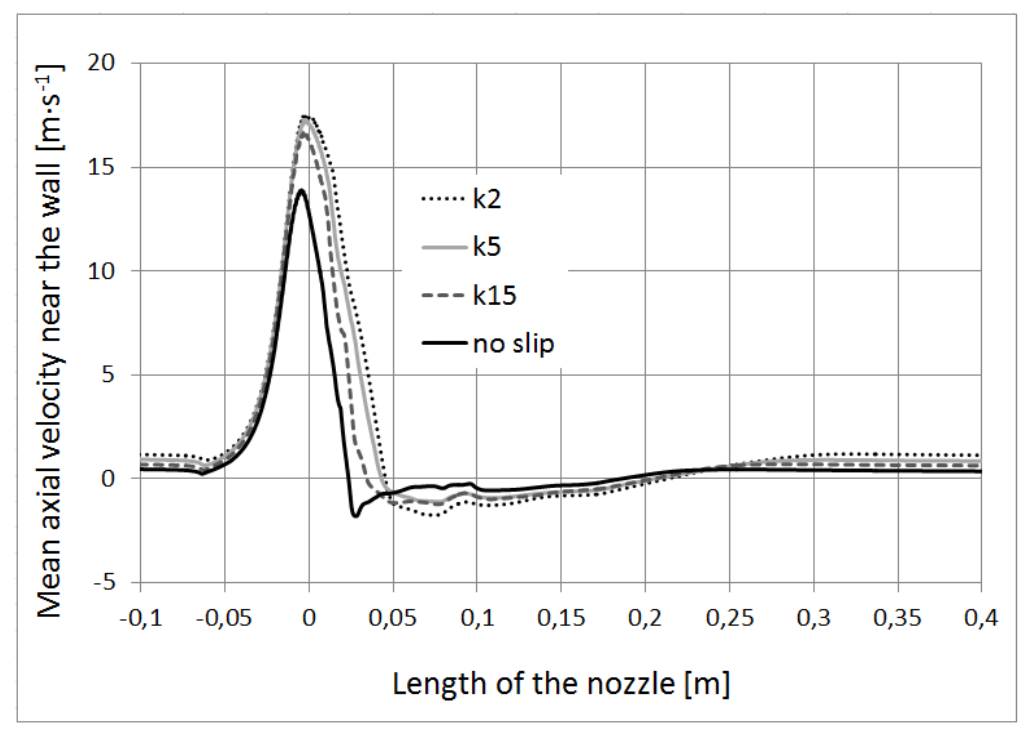

Fig. 14. Mean axial velocity in the first cell by the wall in the narrowest place of the nozzle at different surface wetting

The graph in Fig. 15. describes wall shear stress in the narrowest place of the nozzle. The difference in values for fully wettable and partially wettable walls is evident in the narrowest place of the nozzle. The values of wall shear stress on the wettable surface are highest and with a decrease in wall wetting (i. e. the adhesive coefficient) they are decreasing. 


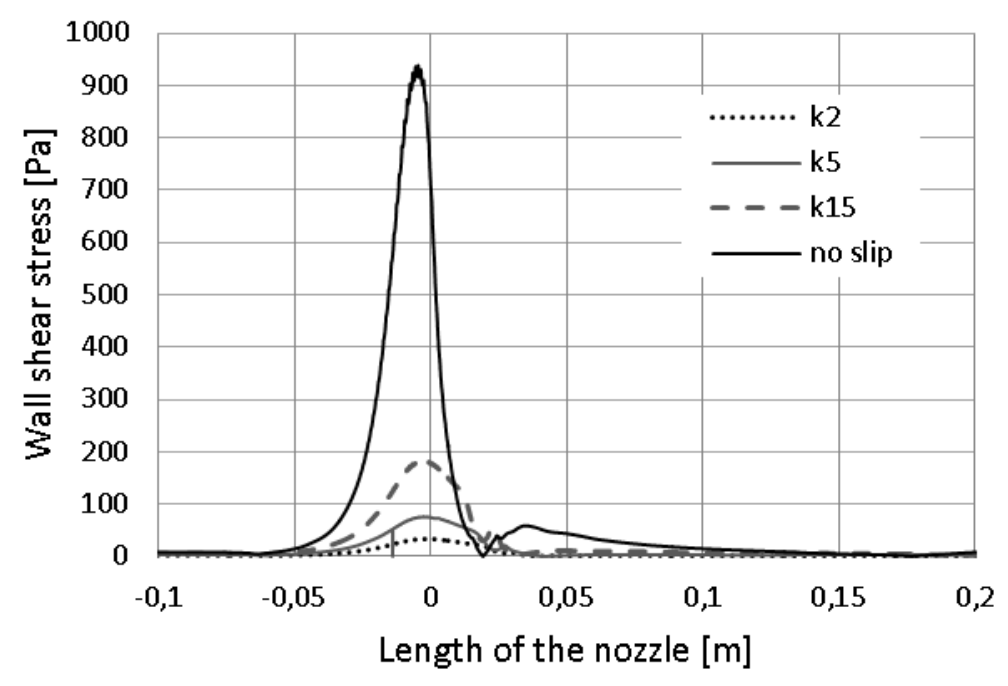

Fig. 15. Wall shear stress in the narrowest place of the nozzle at different surface wettings

\section{Conclusion}

The topic of this article focused on cavitation emerging in the Laval nozzle at specific wettable wall conditions.

The adhesive coefficient $k$ was determined by nonlinear regression, based on a derived mathematical model. The contact angle was determined using the SEE System software. Direct measurement of the adhesive coefficient $k$ and the value calculated by using the least squares method should describe more realistically the quality of the material and the flowing liquid (in this case, water) from the wetting point of view. The most hydrophobic surface was measured on the TC4111 material where the value of the adhesive coefficient was $\mathrm{k}=1,326$, while the most wettable material, TC1191, was $\mathrm{k}=1,6011$.

In case of the fluid flow through the Laval nozzle, cavitation area was observed. The values of the static pressure for predefined mass flow rate, at specific sampling points were measured. The results from this experiment were compared with the results from the numerical computations of cavitation.

Additional research in the theory of partial wetting surfaces was used for numerical modelling of flow through the nozzle. The wetting boundary condition on the wall was introduced in the computational program by UDF function with various adhesive coefficients. The influence of a partial wettable wall on the size and behaviour of the cavitation area in the Laval nozzle was researched. It was confirmed that the cavitation length and volume fraction of the vapour increases with decreasing value of the adhesive coefficient. The axial velocity on the partially wettable wall is not zero. The graphs of mean axial velocity illustrate that with decreasing value of adhesive coefficient $k$ liquid velocity increases. The values of wall shear stress on a wettable surface are highest and with a decreased wetting of the wall (i. e. adhesive coefficient) these values are decreasing.

It is obvious that there is consistency between partial wall wetting and the theoretical assumptions and for their physical verification a future experiment will be prepared. 
It is evident, that the partially wet wall has a positive influence on pressure drop. Due to numerical investigation, the same can be said for cavitation flow, but the shape of cavitation area is deformed. Future research will develop in the domain of partially wettable materials and their use in hydraulic systems.

\section{ACKNOWLEDGEMENTS}

The work presented in this paper was supported by a grant SGS „Výzkum v oblasti dynamiky tekutinových systémů.“ SP2017/103.

This work was supported by The Ministry of Education, Youth and Sports from the Large Infrastructures for Research, Experimental Development and Innovations project "Innovations National Supercomputing Centre - LM2015070".

The work presented in this paper was supported by the Grant Agency of the Czech Republic GA16-18316S.

\section{REFERENCES}

[1] C. E. Brennen, Cavitation and bubble dynamics. Cambridge University Press, 1995.

[2] J. Noskievič, Cavitation. Praha: Czech Academy of Sciences, 1969.

[3] D. Cannizzaro, G. Pezzinga. Energy Dissipation in Transient Gaseous Cavitation. J. Hydraul. Eng., 2005, 724 - 732. DOI: 10.1061/(ASCE)0733-9429 (2005)131:8(724)

[4] M. Čarnogurská. Fundamentals of Mathematical and Physical Modeling in Fluid Mechanics and Thermodynamics. Vienala, Košice. 2000. (in Slovak)

[5] C. E. Brennen. Fundamentals of Multiphase Flow. Cambridge University Press, USA., 2005.

[6] ANSYS FLUENT INC. Fluent 15.0, Help - User’s guide. Fluent Inc., 2012

[7] ANSYS FLUENT INC. Fluent 15.0, Help - Theory guide. Fluent Inc., 2012

[8] D. Bílý, M. Kozubková. Dynamics behaviour of the cavitation field. Journal of Applied Science in the Thermodynamics and Fluid Mechanics, 2011 (9), No. 2, 1-8.

[9] M Kozubková. Mathematical Models of Cavitation and Hydraulic Shock. VŠB-TUO, Ostrava. 2009 (in Czech)

[10] F. Pochylý, S. Fialová, V. Habán, L. Rinka. The Wettability of the Liquid-Solid Interface. FIV 2008 - Flow-Induced Vibration. 2008, 47 - 52.

[11] F. Pochylý, S. Fialová, M. Kozubková, L. Zavadil. Assessment of cavitation creation depending on the surface wettability. 25th IAHR Symposium on Hydraulic Machinery and Systems, 2010 (12), No. 1, 1 - 9.

[12] L. Zavadil, S. Drábková, M. Kozubková, B. Frodlová. The Influence of the Partial Surface Wetting on the Flow Field in a Pipe with Circular Cross-section. Transactions of the Vک̌S - Technical University of Ostrava, Mechanical Series, 2011 (57), No. 1, 267 274.

[13] B. Frodlová, P. Rudolf, L. Zavadil, M. Kozubková, J. Rautová, Effect of Partial Wettability on the Flow and Cavitation Area in the Laval Nozzle. Transactions of ANSYS 2011 Conference, 2011, 1 - 8. (in Czech)

[14] Leighton, T.: The Acoustic Bubble. Physics In Medicine And Biology. Academic Press: 1997, p. 613. ISBN: 978-0-12-441921-6 
[15] Cheremisinoff N. P.: Noise Control in Industry. William Andrew: 1996. 203 p. ISBN: 978-0-8155-1399-5.

[16] F. Pochylý, L. Rinka: Surface energy in the boundary layer of the droplet and the solid surface, research report, VUT, 2007

[17] S. Fialová, F. Pochylý. Identification and experimental verification of the adhesive coefficient of hydrophobic materials, 18th International Seminar on Hydropower Plants, November 2014, Austria

[18] Maklakov D. V., Suleimanov S. Z.: Jet Impingement on a Wall of Arbitrary Configuration. Fluid Dynamics. 2014 (49), No. 4. ISSN 0015 - 4628.

[19] Z. Csuka, R. Olšiak, Z. Fuszko. Research of Cavitation at High Shear Stress. Journal of Mechanical Engineering - Strojnícky časopis, 2016 (66), No. 1, 7 - 16. ISSN 0039-2472

[20] V. Goga, B. Hučko. Phenomenological Material Model of Foam Solids. In Journal of Mechanical Engineering - Strojnícky časopis, 2015 (65), No. 1, 5 - 20, ISSN 0039-2472 
